\title{
MODERN TRENDS IN TEACHERS' ROLES IN DIGITAL ERA
}

\section{Maria Prokopchuk ${ }^{1}$}

DOI: https://doi.org/10.30525/978-9934-26-076-6-15

Having been dealing with COVID-19 consequences and spending more than half of the academic year at home, a great number of teachers grabbed an idea of certain changes in the perception of their role in the educational theatre.

The teaching techniques, that were efficient in the $20^{\text {th }}$ century, stopped working with the generation $\mathrm{Z}$ and especially generation Alpha that will flood higher education institutions in a few years.

The $21^{\text {st }}$ century education depends on Thinking Skills, Interpersonal Skills, Technological Skills as well as Life Skills that not only challenge a modern educator but also demands a set of new roles to apply in class [1].

Due to an instant access to information and the thinking skills to get, process and interpret data there is a necessity to develop thinking skills in modern students that can be stimulated both by an unstructured process such as brainstorming, and by a structural process such as lateral thinking.

Teacher can broaden students' horizons and become a resource provider, showing a number of new resources to use in class.

On the other hand, there is always alert that some students might be more developed experts on some topics.

The second role such as a learning facilitator emerges due to a new lesson objective that is to engage all participants into the learning process, including fast and slow learners. To turn a lesson into an enjoyable trip in contrast to everyday cramming routine is not an easy task.

New apps, learning platforms and language stimulators are a set of teachers' tools implied in class today.

The third role of teachers in digital era is a digital learner for the lifetime. Teachers must be the first to inform their students about lifetime learning approach applied in order to be successful in the digital society.

Keeping a pace with modern trends presupposes another role, which is $\boldsymbol{a}$ future predictor. Interpersonal and life skills (teachers can help students develop them in class) are essential to survive in digital era as well. Teachers' role is to not only predict the near future changes in the society but also bring innovation in class, encouraging students to be flexible and obtain new skills as fast as they can due to modern technologies.

\footnotetext{
${ }^{1}$ Borys Grinchenko Kyiv University, Ukraine
} 
The next role that is closely connected with the mentioned above is a career planner. Teacher are thought to be a society leaders whose role is to foresee the best option in the job market in the near future and be a society prospect generator.

Realizing that fact that future surviving in the digital era will depend drastically on critical thinking, communication, collaboration, and creativity, the teachers' responsibility to equip students with appropriate skills, encouraging them to choose a certain career to be in a great demand and a helping hand for the society.

Maintaining the online community with his students makes a teacher be a technology lover for learning. Every new application to communicate faster, to perceive deeper, to deal with virtual and augmented realities help a teacher inform students about the outer physical and inner virtual worlds we are facing these days.

To recapitulate mentioned above trends in teachers' roles, we can arrive at the conclusion that digitalization, observed in modern education theatre, makes teachers be flexible and work fruitfully on the verge of technology, pedagogy and subject content.

\section{References:}

1. Sardar I. T. Changing roles of teachers in the $21^{\text {st }}$ century (2018). Available at: https://medium.com/@itsardar/changing-role-of-teachers-in-the-21st-century-5acb 47a23a33 (accessed 6 May 2021). 